\title{
MANKIND'S IMPACT ON CLIMATE: THE EVOLUTION OF AN AWARENESS
}

\author{
WILLIAM W. KELLOGG \\ National Center for Atmospheric Research*, P.O. Box 3000, Boulder, CO 80307, U.S.A.
}

\begin{abstract}
The first inklings of an understanding of the role played by infraredabsorbing gases in maintaining the warmth of the surface of our planet were voiced early in the 19 th century, and by the turn of this century quantitative calculations had been carried out that demonstrated how a change in atmospheric carbon dioxide would alter the earth's mean temperature. However, it was not until the 1960 s that much attention was paid to this matter, and in the early 1970 s two important summer studies dealing with environmental change fired the imagination of the scientific community. Since then the science (or art) of modeling the climate system has made great strides, aided by faster computers, greater knowledge of the factors involved, and global observations from space of the atmosphere, oceans, and biosphere. This effort has also been bolstered by studies of the behavior of the climate system in the past. There is now a strong consensus that the observed increase in the atmospheric concentrations of carbon dioxide and other infrared-absorbing trace gases is indeed warming the earth, and that this change is caused by mankind. The next set of questions are now being seriously addressed in national and international forums: what are the regional patterns of the changes to be anticipated, especially in terms of rainfall and soil moisture? And what should the countries of the world do about the situation? There is already a sharp debate between the activists, who would take action worldwide to avoid the climate change (or at least slow its advance), and those who would simply wait and see what happens and perhaps take what local measures are necessary to mitigate the effects.
\end{abstract}

\section{Introduction}

It is common knowledge that the climate inside our large cities is several degrees warmer than that of the surrounding countryside. This comes as no great surprise, since we can feel the sun-warmed pavements in summer, and we are aware - perhaps with a twinge of guilt - of all the heat that leaks into the outdoors in winter. Thus, on a local scale our activities have clearly modified the climate in which many of us live.

But is it possible to change the climate of our whole enormous planet? Everyone knows that there have been major climate changes in the distant past with the waxing of ice ages. These major changes must have been due to combinations of natural influences that affected the heat balance and temperature of the entire earth. How can little creatures like us compete with those titanic forces that drive the winds of the atmosphere and the ocean currents?

Only 25 yr ago few scientists would have expressed much concern over this question. If prodded a bit, one could easily show that the total power output of all human activi-

* The National Center for Atmospheric Research is sponsored by the National Science Foundation. 
ties (about $8 \times 10^{12} \mathrm{~W}$ ) was utterly insignificant (about $1 / 10000$ ) compared to the radiant heat absorbed from the sun. This simple argument seemed to prove that we could not influence the heat balance of the earth nor its climate, and so the matter stood.

But there are always a few independent spirits who are not willing to accept obvious answers without searching for other possibilities. Can there be leverage points in the complex system that determines climate - leverage points that we can reach? (In the modern technological era a better analogy might be a servo, of the sort that allows a pilot to steer a supertanker with the turn of a knob.)

As it turns out, there are indeed some crucial leverage points in the climate system. For one thing, mankind has been changing the face of the earth for many thousands of years. It is common knowledge that most of the dense forests that blanketed northern Europe at the time of the Roman conquests have been cleared for agriculture, and also gone are the forests that used to extend from the Black Sea to the Persian Gulf. Many decades of severe soil erosion in Africa (and elsewhere) coupled with bad agricultural practices and deforestation have permitted the spread of deserts, and there is good reason to believe that deserts tend to perpetuate their own dry climate (e. g., Bryson and Baerreis, 1967; Kellogg and Schneider, 1977).

It is often hard to distinguish between ecological changes that can be directly attributed to human activities and those that were caused by natural processes, but there is no doubt about the fact that the surfaces of large areas of the earth have a different heat and water balance than they used to have, before mankind had a major influence on the vegetation cover. This must surely have had an influence on regional climates, though the effects are hard to quantify (SMIC, 1971; Flohn, 1975). It probably even had a small effect on the global climate (Sagan et al., 1979).

Another way by which mankind has influenced the climate is by changing the composition of the atmosphere. The layer of smog and smoke that hangs over virtually every big city is clear evidence of this fact. It is not so obvious, but nevertheless an established fact, that such air pollution changes the heat balance and rainfall of a region and consequently the climate. This is due to the fact that the particles, or 'aerosols', generated by industry, automobiles, and burning debris absorb solar radiation, and this warms the smog layer while preventing some sunlight from reaching the surface. The result is a more stably stratified lower atmosphere, one that inhibits convection and rainfall over a city (SMIC, 1971; Kellogg, 1980). Downwind, on the other hand, there is evidence that rainfall may actually increase due to the role that some industrial particles play as cloud condensation nuclei or freezing nuclei (Dettwiller and Changnon, 1976). However, this is mainly a regional effect.

The human influence on global climate that is receiving by far the most attention these days is the increase of atmospheric carbon dioxide from the burning of fossil fuels, and also of other trace gases contributed by our intensifying industrial and agricultural activities. The fact that the carbon dioxide concentration in the atmosphere is increasing can be observed, as will be detailed shortly. Since carbon dioxide is just one of several trace gases that absorb infrared radiation emitted by the earth's surface (and all of them are increasing), adding more of the absorber prevents a fraction of the upgoing radiation 
from escaping to space. This warms the lower atmosphere, and consequently the surface as well. The process is often referred to as the 'greenhouse effect', though the analogy to a greenhouse is far from perfect.

\section{History of Understanding of Carbon Dioxide and the Greenhouse Effect}

Since this account concerns the evolution of our awareness of the potential for anthropogenically-induced climate change, it is pertinent to point to the earliest inklings in the scientific literature. Revelle (1985) and Ausubel (1983) have recently published excellent reviews of the early efforts to define the role of carbon dioxide in the atmosphere, from the points of view of both our depletion of the fossil fuel reserves of the earth and also the role of carbon dioxide in sustaining plant life and in regulating the surface temperature. We have drawn on those reviews in this brief summary, but restrict the discussion to the climatic aspects of carbon dioxide.

According to Revelle, the first scientist to propose that the gases in the atmosphere could retard 'heat' radiation (infrared) from escaping to space and thereby warm the surface was the prominent Frenchman, Jean Baptiste-Joseph Fourier (1768-1830). He pointed out that this effect was similar to the glass in a 'hothouse', though it seems that he misunderstood the mode of action of a greenhouse.

Subsequently John Tyndall in England actually measured the absorption of infrared radiation by carbon dioxide and water vapor and showed that these atmospheric constituents could significantly raise the earth's surface temperature (Tyndall, 1863). He was apparently the first to make an important additional deduction, namely that glacial periods may have been caused by a decrease in atmospheric carbon dioxide.

Just before the turn of the century, two remarkable studies appeared that greatly advanced our appreciation of the effects of carbon dioxide changes on climate. It was realized that the concentration of carbon dioxide was probably increasing, as mankind took carbon out of the earth in the form of coal, petroleum, or natural gas and burned it. Svante Arrhenius, a Swedish scientist who received one of the first Nobel prizes in chemistry, attempted to calculate the effect on the average surface temperature of a doubling of carbon dioxide. He used S. Langley's measurements of infrared radiation from the moon as it passed through the atmosphere at different angles above the horizon and at different humidities for his estimates of the atmospheric absorption due to both carbon dioxide and water vapor, and he combined these with independent measures of carbon dioxide to estimate its current optical depth. He then calculated that doubling the carbon dioxide would raise the average surface temperature by 5-6 K, the larger warming occurring at high latitudes. A decrease of carbon dioxide to two-thirds of the present would cause a cooling of 3 to $3.4 \mathrm{~K}$, he wrote. In these calculations he took into account the likely increase of total water vapor content with increasing temperature, an important 'feedback mechanism' (though that term would not be invented until some $50 \mathrm{yr}$ later). On the basis of his calculations he deduced correctly that if the quantity of carbonic acid [carbon dioxide] increases in geometric progression, the augmentation of the temperature will increase nearly in arithmetic progression' (Arrhenius, 1896, 1908). 
The American geologist-turned-college-president, Thomas C. Chamberlin (he was president of the University of Wisconsin), built on the insights provided by Arrhenius to 'frame a working hypothesis of the cause of glacial epochs on an atmospheric basis' (Chamberlin, 1899). Much of his argument deals with the changes in sea level relative to the continents and the effects these would have on the weathering of silicate rocks and atmospheric carbon dioxide depletion, a matter also treated by Arrhenius. Chamberlin suggested a mechanism involving the effects on sea level of continental ice sheets, and, among other things, showed that this could result in the cyclic behavior of glaciations and interglacials in the last million years or so as the balance between carbon dioxide removal by weathering of rocks and replenishment by volcanic emissions was altered. (An alternative theory based on cyclic perturbations of climate due to changes in the earth's orbit and axis of rotation was to be suggested by Milankovitch [1930] some 30 yr later, but nevertheless Chamberlin's hypothesis involving carbon dioxide is a reasonable explanation of cyclic climatic variation throughout later geologic time.)

It is interesting to note that an important aspect of this hypothesis, namely the role that the oceans play as a major reservoir of carbon dioxide, was recognized by Chamberlin and studied by one of this students, C. F. Tolman (1899). Although relatively little was known then about the exchange rates of water masses within the oceans and their influence on storage times of carbon dioxide, the early insight provided by Tolman on this aspect of the question was notable.

Thus, it seems that many of the important pieces of the carbon dioxide/climate puzzle were in place by 1900 , though of course there were serious gaps in the knowledge of rates of removal and replenishment of carbon dioxide, and also of many other factors that influence the climate system. Furthermore, it would have been virtually impossible at that time to foresee that the worldwide use of fossil fuels would grow exponentially at a rate of about 4 percent per year for the next $73 \mathrm{yr}$, and even after that continue to increase at a substantial rate. When Arrhenius made his calculations in the 1890 s of the effects of doubling or tripling the atmospheric concentration of carbon dioxide, the time when that would occur must have seemed very far in the future indeed. (We will see shortly that it is probably not so far away after all.)

Nevertheless, the intriguing idea that mankind could raise the earth's temperature seems at first to have attracted surprisingly little attention in the scientific community and even less in the public media. It was treated in several papers and books in the $1920 \mathrm{~s}$ and 1930s, notably by biologists or ecologists who were more interested in the global carbon cycle and the squandering of a virtually irreplaceable natural resource, namely, our store of fossil fuels. The implication that climate could be impacted seems to have been of less interest or else utterly ignored.

The importance of the carbon dioxide-climate issue was beginning to be recognized and addressed by a larger community by the 1950 s and, for example, John von Neumann (1955) wrote about the possibility of 'climate control'. In 1957 Roger Revelle and Hans Suess, two scientists at the Scripps Institution of Oceanography, made a statement in an article in Tellus that has been repeated many times: 'Human beings are now carrying out a large-scale geophysical experiment', namely testing the greenhouse effect of carbon 
dioxide by actually changing its atmospheric concentration. They also pointed out that the newly added carbon dioxide would probably remain in the atmosphere for many centuries because of the slowness with which the oceans could absorb it (Revelle and Suess, 1957).

In the post-IGY period there was a growing general awareness of what might be taking place as a result of our 'geophysical experiment'. In 1963 the Conservation Foundation sponsored a meeting on this topic, and its report stated the situation more clearly than any before it: 'It is estimated that a doubling of the carbon dioxide content of the atmosphere would produce a temperature rise of 3.8 degrees (Celsius)' - though the time scale involved is left unspecified (Conservation Foundation, 1963).

Just two years later, in 1965, the august President's Science Advisory Committee (PSAC) published under the White House seal a report of its Environmental Pollution Panel entitled, Restoring the Quality of Our Environment (PSAC, 1965). (The Panel's Chairman was John Tukey, and Roger Revelle was Chairman of the Sub-Panel on Atmospheric Carbon Dioxide. Other members of that Sub-Panel were Wallace Broecker, Harmon Craig, Charles David Keeling, and Joseph Smagorinsky.) The PSAC report deals with many aspects of air and water pollution, but it will also be remembered as a first public recognition in a United States government document that climate change could be caused by human activities and that this would have important consequences for the world.

\section{The 20th Century Record of Carbon Dioxide and Other Greenhouse Gases and Conjectures about the Future}

It was during the International Geophysical Year (IGY) that Revelle's colleague at the Scripps Institution of Oceanography, Charles David Keeling, started his now-famous nearly continuous monitoring of carbon dioxide at the Mauna Loa Observatory on Hawaii and at the South Pole. While there have been short interruptions in the record (for example, at the South Pole in 1963 for about one year), these two stations have given us the best picture available of the rise of carbon dioxide from 1958 onward (Keeling et al., 1984). This is shown in Figure 1. Needless to say, during the 1960s and 1970s there were other monitoring stations set up by NOAA's Global Monitoring for Climate Change program, and now the extensive global effort to monitor atmospheric concentrations of trace gases is being encouraged and coordinated internationally by the World Meteorological Organization (WMO), the International Council of Scientific Unions (ICSU), and the United Nations Environment Programme (UNEP) (Wallen, 1980; Gammon et al., 1985).

It should again be emphasized that carbon dioxide is not the only trace gas whose atmospheric concentration is increasing as a result of human activities, and that most of those other gases are long-lasting in the atmosphere and are also good absorbers of infrared radiation. They are often referred to together as 'greenhouse gases', since the presence of all of them tends to warm the lower atmosphere. Some of the other gases in question are the chlorofluorocarbons (CFC's) used as a propellant in spray cans and 


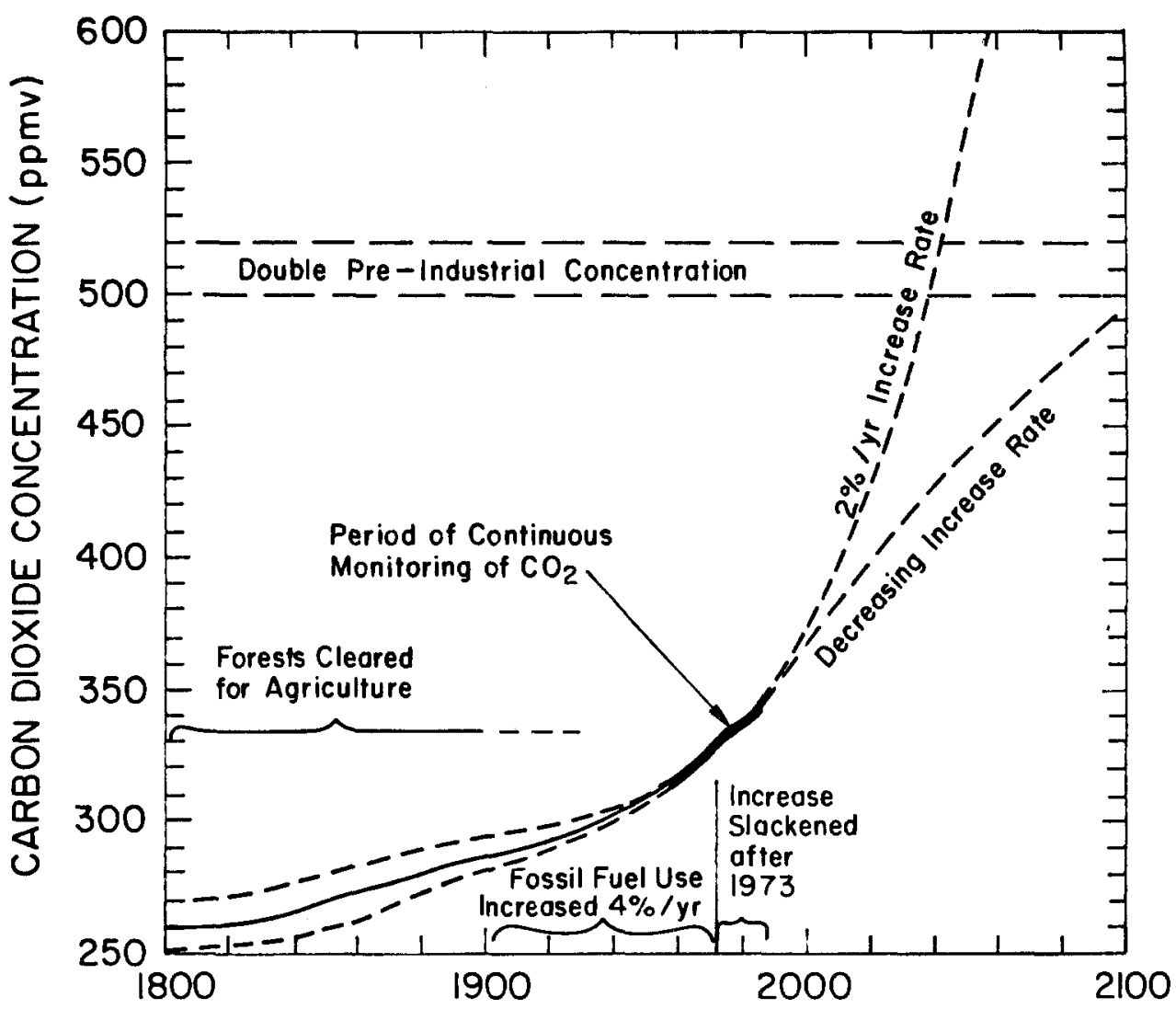

YEAR

Fig. 1. Past and future changes in atmospheric carbon dioxide concentration, measured in parts per million by volume (ppmv). Some increase probably occurred in the 19th Century due to extensive clearing of forests and the conversion of biomass to carbon dioxide (a process still going on), though there were few direct measurements in that period. During most of this Century fossil fuel burning and the consequent production of carbon dioxide increased at a rate of $4 \% \mathrm{yr}^{-1}$, but in 1973 there was the OPEC oil embargo and a worldwide recession resulting in a definite slackening of the rate of increase (see Clark, 1982). A good guess is that future consumption of fossil fuels will lie somewhere between a continuing $2 \% \mathrm{yr}^{-1}$ of increase ('high') and a linearly decreasing rate of change such that 50 yr from now we will return to the present level of consumption ('low'). For the high case the concentration of carbon dioxide will be double that of the pre-Industrial Revolution level before the middle of the next Century; for the low case it may be about 100 yr later.

also in refrigerators and air conditioners, methane, nitrous oxide, and ozone. Since their concentrations in the atmosphere are increasing even more rapidly than carbon dioxide (Rasmussen and Khalil, 1986), it is expected that early in the next century the contributions of all those other gases to a global warming could nearly match that of carbon dioxide alone (Ramanathan et al., 1985). For this reason they are all being monitored at stations scattered throughout the world, from Point Barrow, Alaska, to the South Pole Station.

What have we learned about the trends of carbon dioxide concentration (and those of 
the other greenhouse gases) from all these measurements? When Keeling started his measurements during the IGY, the concentration at the South Pole and Mauna Loa was between 312 and 313 parts per million by volume (ppmv), and now it has climbed to about 345 ppmv, as shown in Figure 1. Before the Industrial Revolution and the widespread burning of fossil fuels, and before we had embarked on the large-scale clearing of forests for agriculture in the 19th Century, it is estimated from air samples trapped in ice cores that the concentration of carbon dioxide was 250 to $270 \mathrm{ppmv}$ - that's an increase of 20 to $30 \%$ in less than $200 \mathrm{yr}$ (Oeschger et al., 1985; Gammon et al., 1985). So there is no doubt at all that we have been raising the level of carbon dioxide in the atmosphere by our activities, both industrial and agricultural.

Though it may be getting ahead of our story, it is natural that we should try to estimate what will take place in the future, assuming that mankind will continue to burn fossil fuels and that more carbon dioxide will be added to the atmosphere each year. This will obviously depend on what mankind will require in the way of energy and the methods used to generate it, whether fossil fuel, nuclear, solar, wind, or other 'renewable energy sources'. We have no very rational way to predict this, so one procedure is to invoke two possible scenarios of fossil fuel use, a very 'high' and a very 'low' scenario, with the real course presumably lying somewhere in between. I have chosen the 'high' scenario to be a continuation of the $2 \% \mathrm{yr}^{-1}$ rate of increase that has prevailed since 1973 (Rotty and Masters, 1985; Rotty and Marland, 1986); for the 'low' scenario I have assumed a linear decrease of the rate of increase of fossil fuel use such that in $50 \mathrm{yr}$ it has returned to the present annual consumption (Kellogg, 1979). It is further assumed that the fraction of new carbon dioxide remaining in the atmosphere (the 'airborn fraction') remains at its average historic level of about 55\%. The results are also shown in Figure 1.

Note that the time when the atmospheric concentration reaches twice its preindustrial concentration (a kind of milestone invoked by Arrhenius in 1896 and still used by climate modelers) is in the first half of the 21 st century for the 'high' scenario, but some time after $2100 \mathrm{AD}$ for the 'low' scenario. This provides a rough time scale for the growth of carbon dioxide. However, also note that the temperature change in that future period will presumably be hastened by the addition of other greenhouse gases as already emphasized (Ramanathan et al., 1985); and slowed for a few decades by the thermal inertia of the oceans (Schneider and Thompson, 1981; Hoffert and Flannery, 1985).

\section{Recent Studies of the Effects of Mankind on Climate}

The general pictures of what was understood in the post-IGY period and the outlines of the theory of a greenhouse gas-induced climate change has been described above, not necessarily in a historical or chronological order. Consider now the situation as it existed in the late 1960s. The PSAC Report of 1965 had called the attention of the world to the distinct possibility that the earth could become warmer as a result of human activities, and a handful of scientists on both sides of the Atlantic were beginning to develop a physical theory to explain the behavior of the complex system that determines climate (e. g., Manabe and Wetherald, 1967; Sellers, 1969; Budyko, 1969). 
The time was ripe then to address the question of global environmental problems and the scope of human activities in a more systematic and quantitative way. The most monumental effort up to that time to actually mount a study of this kind was that led by Carroll L. Wilson, M. I. T. Professor of Management. He organized a distinguished Steering Committee to plan what came to be called the Study of Critical Environmental Problems, or 'SCEP' for short. The SCEP took place for the entire month of July 1970 at Williams College in Williamstown, Massachusetts, and involved approximately 40 scientists and professionals drawn from over a dozen different disciplines. The Associate Director of the Study was William H. Matthews of the M. I. T. Political Science Department.

The major objective of SCEP, as stated in the Preface of the report by Wilson and Matthews (SCEP, 1970), was 'to raise the level of informed public and scientific discussion and action on global environmental problems', and this it did. There were seven work groups in all, each one dealing with an environmental discipline, or else gathering global statistics - mostly economic and industrial - that could be used by the disciplinary working groups.

As I was Chairman of the Work Group on Climatic Effects, I will confine my remarks to that part of the Study. I think it is fair to say that virtually every member of that Work Group came away with a heightened awareness of the subject with which we were dealing, and a sense of the totality of human impacts on the environment. On the subject of carbon dioxide and climate, we were emphatic about its importance but noncommittal about the magnitude or time scale of the change in store for the world. I believe that what we concluded was about as strong a statement as could have been made at that time, to wit:

Although we conclude that the probability of direct climate change in this century resulting from $\mathrm{CO}_{2}$ is small, we stress that that long-term potential consequences of $\mathrm{CO}_{2}$ effects on the climate or of social reaction to such threats are so serious that much more must be learned about future trends of climate change. Only through these measures can societies hope to have time to adjust to changes that may ultimately be necessary (SCEP, 1970, p. 12).

We also spoke out on the subject of air pollution by particles, on the effects of cirrus clouds from jet aircraft, on surface changes such as deforestation, and on the effects of supersonic transports (SSTs) on climate and the ozone layer. The media representatives that came to Williamstown to be briefed on the SCEP results were most intrigued by the last item, since there was already a debate going on in Congress about the Federal appropriation for building two prototype SSTs, and they were relatively less interested in climate change.

It was clear, at any rate, that the SCEP had indeed 'raised the level of . . scientific discussion ... on global environmental problems', and Carroll Wilson decided to seize the opportunity to organize a followup that would involve the international scientific community. As usual, he was successful. Again he obtained financial support from a variety of governmental organizations, private foundations, and corporations; and the Royal Swedish Academy of Sciences and the Royal Swedish Academy of Engineering Sciences offered to be our hosts. The meeting took place at a conference center in Wijk, near Stockholm, for three weeks in July 1971. And again William Matthews was the 
Associate Director, and I participated as one of the 'secretaries' - the other was G. D. Robinson, a former President of the British Royal Meteorological Society.

This time the discussion focused more sharply on the question of climate change, and the report was entitled The Study of Man's Impact on Climate, or 'SMIC' for short. (In this day and age we would probably have substituted Mankind for Man.) It was to provide 'an authoritative assessment of the present state of scientific understanding of the possible impacts of man's (sic) activities on the regional and global climate' (SMIC, 1971). More than a decade later one can look back at this book with some perspective, and $I$ think it is fair to say that it did indeed serve as an authoritative source of information on virtually all aspects of the question of climate change and many related subjects - though bit by bit some things in it were overtaken by new advances of science and have become outdated, as will be pointed out.

It is particularly notable that the following year (1972) witnessed the first United Nations Conference on the Human Environment (in Stockholm), and the SMIC Report was said to be 'required reading' for all participants. The fact that no very binding agreements were reached at that U. N. Conference can hardly be blamed on our book. One useful outcome of the Conference was the decision to found a new organization devoted to the preservation of the global environment, the U. N. Environment Programme (UNEP).

There were many aspects of the SMIC experience that stick in my mind, but two stand out as worth recording for posterity - they are not mentioned in the formal Report. (The first reveals something about Carroll Wilson, the Study leader, and the second underscores our state of knowledge of climate in 1971.)

At our first dinner in the Wijk dining hall Carroll made a characteristically gracious welcoming speech to the distinguished scientists gathered from many parts of the world, and he announced that one of the policies that would be followed for the next three weeks was that everyone should adopt the indelicate American habit of calling people by their first names. I know this came as a bit of a shock to some of the scientists there, who would never have stood for such a thing in their home institutions. By the same token, their first names or nicknames were often well-kept secrets, so Carroll asked each participant to jot down his or her preferred appelation. (As I recall, only one scientist could not adapt to this breach of academic etiquette, and we had to be careful to address him alone as 'Professor ')

Toward the end of the study, after most of our conclusions were out on the table, I was intrigued by the apparent impasse in the assembled group between two opposing schools of thought: the climate 'coolers' and the climate 'warmers', if you will. It depended on whether you came from the atmospheric particle or aerosol camp, or the carbon dioxide and infrared-absorbing gases camp.

It was generally thought in 1971 that industrial and agricultural aerosols served to both absorb and scatter sunlight back to space, wherever they were, and that this would mean less sunlight reaching the surface and a net cooling. (Now that we know a lot more about the radiative influence of aerosols, we recognize that this is not necessarily true and a greatly oversimplified view, e.g., Kellogg et al., 1975; Kellogg, 1980; Coakley et al., 1983.) As already explained, the carbon dioxide-and-other-infrared-absorbing-gases 
people recognized the greenhouse effect and its warming influence. There were some other human activities that could tip the balance as well, such as clearing forest land for agriculture, irrigating deserts, creating large artifical bodies of water, and so forth, but these did not seem to us to be quite as important in the short term as the changes in the atmosphere.

So we decided to call an evening meeting to thrash out a consensus, and to decide (if we could) whether we would predict a net cooling or a warming in the decades ahead due to man's activities. It would clearly be useful if we could make such a prediction with some degree of conviction. However, the impasse prevailed, much to my disappointment. There were just too many honest differences of opinion and not enough facts at hand to resolve them.

Additionaly, there was a clear reluctance on the part of many of those colleagues (and of others not at Wijk) to make any predictions at all about the future - to 'stick out one's neck'. Scientists are trained to be cautious about jumping to conclusions too fast, and furthermore we will always be awed by the complexity of the planetary climate system and aware of our inability to understand all its interactions. In the end the SMIC Report states that it is definitely within mankind's power to change the global climate, but there is no further indication of what will probably happen - just what could happen, and possibly with serious consequences.

That was the fairest statement that could be made by the climatological community in 1971. And it helped to fuel the fires of climate research around the world, especially in the United States. A quantitative theory of climate was emerging, primarily as a result of early research in the United States and the Soviet Union, and our computers were increasingly able to handle complex numerical models of the climate system. Bit by bit the pieces of the climate picture were fitted into place.

Such a process is necessarily a gradual one, with many individual contributions and much discussion and some confusion at each stage, but as usual there were certain milestones that served to mark the progress. One was the International Symposium on LongTerm Climate Fluctuations, sponsored by the World Meteorological Organization (WMO) and held in Norwich, England, the summer of 1975 (WMO, 1975). Among other revelations at the Symposium was the finding that low-lying industrial aerosols, and also smoke particles from slash-and-burn agricultural practices, absorb sunlight quite strongly and do not cause a cooling of the lower atmosphere when they are over land - which is, of course, where most of this form of air pollution is found (Kellogg et al., 1975). This seemed to remove the impasse encountered a few years earlier at Wijk, and left the greenhouse warming to dominate the stage.

Another step taken by the WMO was to invite me to prepare a Technical Note entitled Effects of Human Activities on Global Climate (Kellogg, 1977). I relied heavily on the SMIC Report, of course, but was able to bring together a great deal of further information that was simply unavailable in 1971. Notable were some better estimates of the greenhouse warming for a given increase in carbon dioxide and other related factors. These were worked out by such people as Suki Manabe of the Geophysical Fluid Dynamics Laboratory in Princeton, (a SMIC participant), William Sellers of the University of 
Arizona, Stephen Schneider of NCAR (also a SMIC participant), and Michael Budyko of the Main Geophysical Observatory in Leningrad (another SMIC participant). In that report I combined the effect of increasing carbon dioxide on global temperatures with a range of estimates of future fossil fuel consumption (see Figure 1) and drew a 'temperature-versustime scenario" curve out to the year 2050. Even though this exercise was accompanied by many caveats and warnings not to take this prediction too seriously, it seems to have captured the imagination of a great many people both inside and outside the climatological community. A more recent version of this temperature scenario is reproduced here as Figure 2.

A major milestone was a report of a 1979 summer study sponsored by the U. S. National Academy of Sciences (at Woods Hole) at which a blue-ribbon group of meteorologists (and an oceanographer) sought to determine whether the various climate models that were being depended on to relate the greenhouse warming to increased carbon dioxide were scientifically based, and whether they were reliable enough to be believed as simulators of the behavior of the real climate system. This ad hoc committee was chaired by Jule G. Charney, then head of the M. I. T. Meteorology Department, and a scientist who had not up to then become directly embroiled in the carbon dioxide-climate change debate. Its conclusion was that there was no good reason to reject the finding that a doubling of carbon dioxide concentration from the pre-Industrial Revolution value of about 260 ppmv would cause an average global warming of $3 \pm 1.5 \mathrm{~K}$, and that such a warming could occur sometime in the 21 st century (NAS, 1979). (See Figures 1 and 2.)

The 'Charney Report', as it is often called, did not add much to our fund of knowledge about the theory of climate change. However, it did provide some much-needed assurance that our pictures of how the planet would respond to a carbon dioxide change were scientifically sound and believable - at least, to the extent that human ingenuity and computer capacity would allow.

That same year a much larger international gathering was convened to deal with all aspects of climate variability and change. The occasion was the historic World Climate Conference, organized and hosted by the WMO in Geneva in February, 1979. Several hundred scientists and dignitaries attended this week-long conference, and the last two days were devoted to meetings of smaller working groups to review the terms of reference of the proposed international World Climate Programme (much of which I had helped to write). Throughout this week a Conference Statement was discussed and drafted and redrafted, and at the final Plenary Session the Chairman, Robert M. White, was able to obtain agreement on this Statement.

The Statement is too long to repeat here, but one of its most significant points was as follows:

It is possible that some effects on a regional and global scale may be detectable before the end of this century and become significant before the middle of the next century. This time scale is similar to that required to redirect, if necessary, the operation of many aspects of the world economy, including agriculture and the production of energy. Since changes in climate may prove to be beneficial in some parts of the world and adverse in others, significant social and technological readjustments may be required (WMO, 1979, p. 714). 


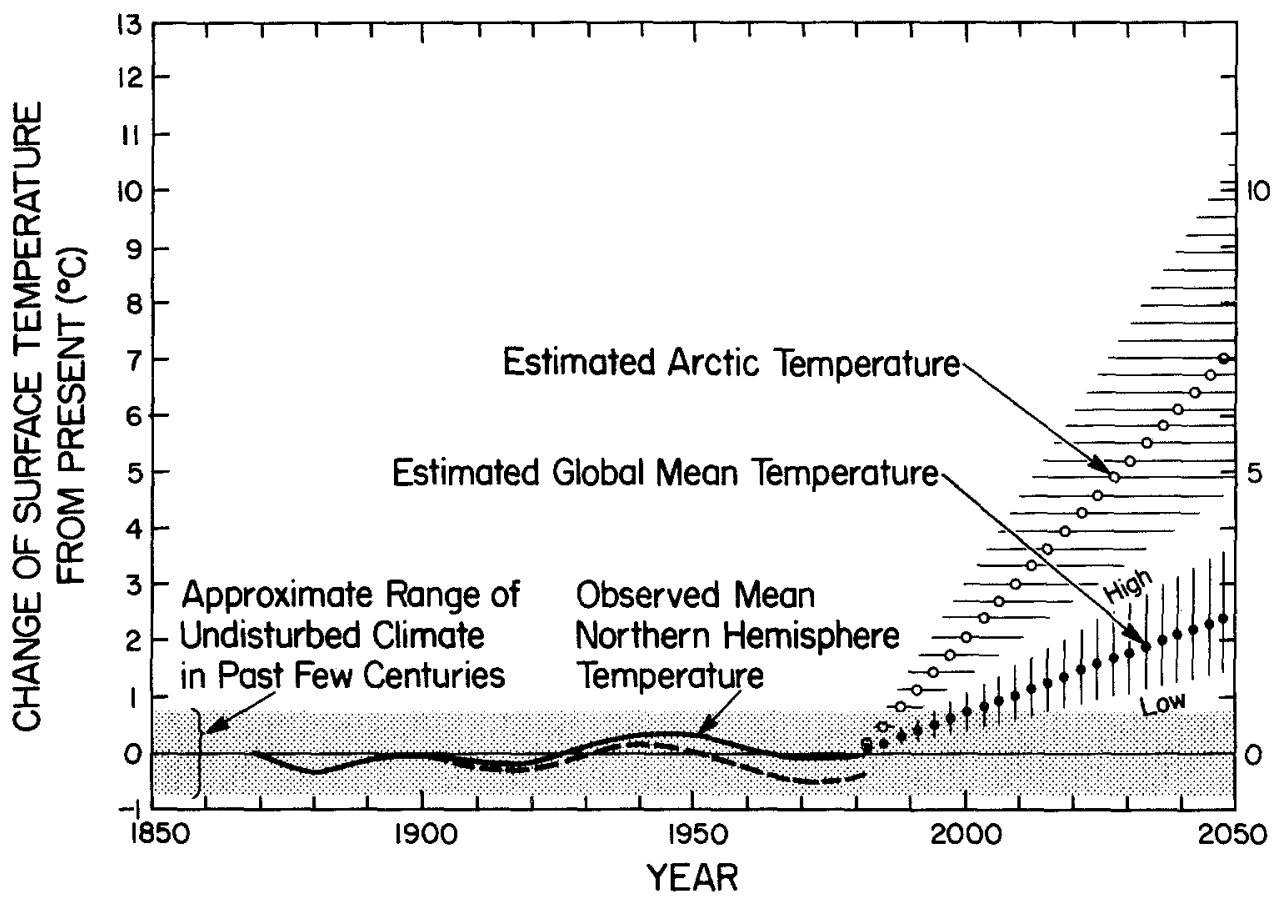

Fig. 2. Estimates of past and future temperature variations. The future changes of global mean surface temperature are based on a $3{ }^{\circ} \mathrm{C}$ warming for a doubling of carbon dioxide concentration, and the possible range between a high and a low scenario is the same as in Figure 1. Changes in the Arctic are expected to be about three times larger than the average. The shaded area shows the range within which the earth's temperature has remained for the past 1,000 years or more. The dashed line is the hypothetical global temperature record that might have occurred if there had been no increase in carbon dioxide or other infrared absorbing gases. The rate of global temperature change shown here will be slowed by the thermal inertia of the oceans and hastened by the contributions of other trace gases to the greenhouse effect. (Source: Kellogg and Schware, 1981, 1982.)

The statement went on to call on all nations to unite in efforts to understand this climate change and to plan for it - and perhaps to lessen its effects. It detailed many of the climate-related problems that had to be solved by scientific research. It concluded with the thought that such international cooperation could only prosper in a world at peace, a rather obvious and most appropriate observation.

\section{The Activists and the Muddlers-Through}

Notice that the Statement of the World Climate Conference does not call for international action to prevent the future climate change, though this point was discussed at the time. In every group there are activists whose instinctive response to an apparent threat is to counterattack, and by opposing end the threat. This is a particularly enticing notion when one is faced with such a convincing scenario of a future earth warmed by carbon dioxide and other greenhouse gases - an insight that mankind has never experienced before (neglecting the story of Joseph in Egypt as recounted in Genesis).

The debate between the activists and the adaptation or 'muddling through' schools 
of action can be illustrated by the decision tree shown in Figure 3. Indeed, this debate has continued ever since the World Climate Conference and with an increasing fervor. No one seems to have a generally acceptable formula for dealing with climate change, but that does not seem to dampen the debate.

Addressing first the left-hand side of the decision tree, there are a number of reasons for thinking that the nations of the world would not unite to prevent the impending climate change. After all, this would require that the use of fossil fuels be banned, or at least drastically reduced, on a worldwide scale. Is there any international mechanism that could make such a drastic decision, and then enforce it on the world? The answer is, of course, a definite ' $N$ ' - and I seriously doubt that such a mechanism could be invented in the foreseeable future (Kellogg and Schware, 1981, 1982). Furthermore, there are enormous vested interests involved in the production and use of fossil fuels, and they would be opposed to any such action. Also, as pointed out by the World Climate Conference, there will be some 'winners' and some 'losers' as the climate change progresses, and those countries that perceive themselves as becoming better off on a warmer earth will certainly not wish to sacrifice the use of that least expensive and most convenient source of energy - fossil fuels. (In a moment I will suggest a remotely possible exception to the above contention.)

While a voluntary limitation on the burning of fossil fuels by the community of nations seems unlikely, it is pertinent to note that a limitation on the production of another type of greenhouse gas, the chlorofluorocarbons (CFC's), may actually take place. The CFC's are notable (or notorious) for their ability to reduce the concentration of ozone in the stratosphere by photochemical interactions between ozone and the halogens carried as part of the CFC molecules. A stratospheric ozone depletion would allow more solar ultraviolet radiation to penetrate to the surface, raising the spectre of more skin cancers in the human population. In December 1986 an international conference sponsored by the U. N. Environment Programme (UNEP), the U. S. Environmental Protection Agency (EPA), and the Alliance for Responsible CFC Policy (a coalition of 500 U. S. companies) met to discuss the proposal for 'a reasonable global limit on the future rate of growth of . . CFC production capacity' (Weisburd, 1986). If such a 'global limit' can indeed be achieved voluntarily, this will mark a major step forward in the history of international efforts to reduce or slow environmental degradation and change. Note,

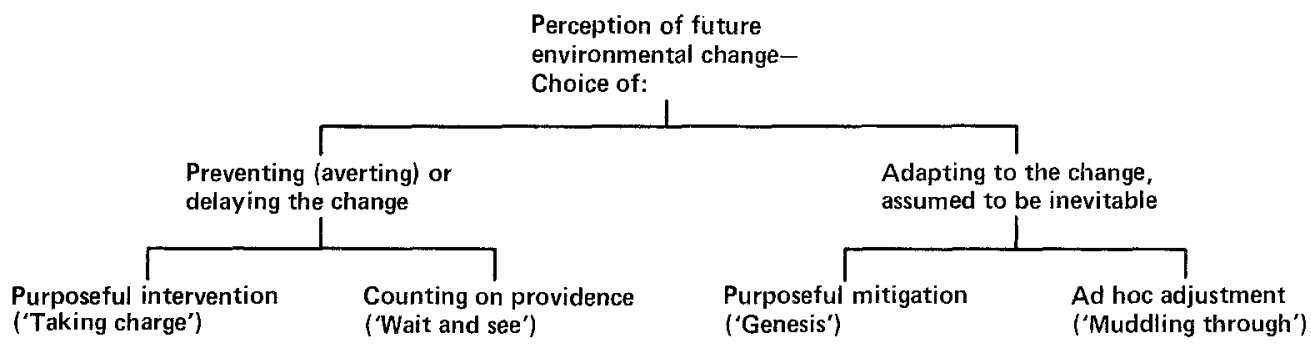

Fig. 3. A decision tree, showing the range of possible policy choices when faced with impending climate change. 
however, that it was primarily the effect on ozone and not on the earth's temperature that seems to have inspired this proposal.

It has frequently been stated that the carbon dioxide/climate problem may correct itself, since we may run out of fossil fuels, notably petroleum and natural gas. The fact of the matter is, however, that there are enormous reserves of coal in the United States, the Soviet Union, China, and Australia. These could last for several centuries at least. The outstanding question is whether the economic and industrial infrastructures can be developed in the decades ahead to convert to the use of coal - even granting that largescale use of nuclear power may gradually emerge in the same time frame.

Again it was Carroll Wilson who recognized and addressed this problem. Following on the footsteps of the Workshop on Alternative Energy Strategies (WAES), which he had directed, he organized the World Coal Study (WOCOL) in 1978 (Wilson, 1980). This was another international effort, and Carroll drew together a working group from 16 countries (those using 75\% of the world's energy). The main messages of the comprehensive report that ensued can be gleaned from the titles of the two parts: 'The Need for Coal' and 'Building the Bridge' - the latter referring to the technical, economic, and logistic issues to be faced in converting to a massive coal-based energy infrastructure.

Suppose that coal did indeed become the main source of energy for the world, at least in the realm of fossil fuels, as suggested by the WOCOL Report. As just pointed out, the major deposits of coal lie in the United States, the Soviet Union, and China - with a distant fourth being Australia. And then suppose that these three superpowers perceived that the climate change due to increasing carbon dioxide was hurting themselves even more than the rest of the world - a distinct possibility, as will be shown. They might then agree to prohibit the export of coal and take measures internally to control its use. This scenario of future developments seems a bit fanciful now, but it is a fascinating example of the sort of socio-economic upheavels that might transpire under the pressure of climate change.

In spite of what has just been said, it seems that we are not very likely to take measures to avert the climate change in store for the world - quite the contrary. Thus, the prudent thing is to prepare for it. There are a number of measures that should be taken to mitigate the adverse effects of climate change and to take advantage of the opportunities presented. Some examples of these measures are to protect arable soil from erosion, to replant forests, to improve water management, to apply agrotechnology to the development of farming techniques suitable for a variety of climates, to provide better climate data and climate monitoring, and so forth (Kellogg and Schware, 1981).

It is highly pertinent to note that those measures taken to prepare for a gradual climate change, assumed to be inevitable, are measures that make good sense anyway. They are things that will help to cope with short-term climatic events as well, such as floods, droughts, hot and cold spells, and they will generally increase our ability to adapt to change.

The debate to which I have referred between the activists or intervenors and the adaptors or muddling-through camps can be illuminated by analyzing the conclusions of two recent prestigious studies. The first is the U. S. National Research Council (NRC) 
report entitled Changing Climate (NRC, 1983a), and the second is the report of the WMO, UNEP, and ICSU International Conference held at Villach, Austria, in October 1985, bearing the imposing title International Assessment of the Role of Carbon Dioxide and of Other Greenhouse Gases in Climate Variations and Associated Impacts (Conference Statement, 1985).

The NRC report is an excellent review of where we stand in our understanding of climate change and its many implications, and, of course, it calls for more research on the subject. It discusses the alternative policies suggested to deal with climate change (see Figure 3), and the chapter by Harvard's Thomas C. Schelling is a particularly incisive statement on the options available to individuals and nations to prevent or adapt to the climate change in store for the world. But when it comes to a recommendation about what should be done about the current situation there is a no clarion call for immediate action. Rather: 'In our judgment, the knowledge we can gain in coming years should be more beneficial than a lack of action will be damaging ... Our stance is conservative: we believe there is reason for caution, not panic' (NRC, 1983a, pp. 61 and xiii).

The statement of the Villach conference, while still calling for more research (of course), has a somewhat different ring. It notes that many important decisions are being made 'based on the assumption that past climatic data, without modification, are a reliable guide to the future', which is no longer valid in view of the 'significant warming of the global climate in the next century'. The final Conference recommendation does not have so much to do with science as with future policy:

Support for the analysis of policy and economic options should be increased by governments and funding agencies. In these assessments the widest possible tange of social responses aimed at preventing or adapting to climate change should be identified, analyzed and evaluated. These assessments should be initiated immediately and should employ a variety of available methods. Some of these analyses should be undertaken in a regional context to link available knowledge with economic decision-making and to characterize regional vulnerability and adaptibility to climatic change. Candidate regions may include the Amazon Basin, the Indian subcontinent, Europe, the Arctic, the Zambezi Basin, and the North American Great Lakes (Confërence Statement, p. 3, italics added).

The statement went even further in suggesting that action might indeed be taken to avert the climate change:

While some warming of climate now appears inevitable due to past actions, the rate and degree of future warming could be profoundly affected by governmental policies on energy conservation, use of fossil fuels, and the emission of some greenhou se gases (Loc. cit., p. 1).

We should add parenthetically that, as in virtually all large scientific debates, there is a small but vociferous handful of dissenters from the consensus of the scientific community. They are apparently skeptical of the idea that a global warming is indeed taking place. Whatever motivates them, they are applauded by the nonscientific public sector that finds the thought that we are tampering with the earth's climate distasteful - perhaps a kind of tribal guilt feeling that we are fooling with Mother Nature. One of the more outspoken of these dissenters argues that all the climate modelers are exaggerating the effect of the carbon dioxide greenhouse effect by about an order of magnitude, and adds the happy thought that the added carbon dioxide will encourage plant growth (the last is 
probably true, but irrelevant to the climate issue) (Idso, 1980, 1982). Unfortunately, considerable effort has had to be expended to demonstrate that such arguments are fallacious (e. g., Schneider et al., 1980; Ramanathan, 1981; Smagorinsky, 1983).

If any further justification were needed to support the contention that the climate change predicted by the theoretical models is actually taking place, we can turn to the temperature record itself. The most recent analysis of the global mean surface temperature from 1861 through 1984, taking proper account of both land observations and those at sea, shows that there has been a slow warming trend of 0.6 to $0.7 \mathrm{~K}$ in that period (Jones et al., 1986). This is entirely consistent with the model results based on the increase of carbon dioxide concentration in the same period, and there is no other convincing theory to explain this warming trend (WMO, 1982).

\section{Future Changes, Scenarios, and Impacts}

At this point it is important to say a word about the crucial homework left for climatologists and those trying to estimate the impacts of future climate change. While a good deal can be said about the global aspects of the increase of carbon dioxide and the other infrared-absorbing gases resulting in the greenhouse effect, this kind of information is simply not very useful to political or managerial decision-makers. It is not enough to tell them that the world will be warmer, when what they need to know is the kind of changes to be expected here - wherever 'here' turns out to be. And it is the changes in rainfall and soil moisture on a regional scale that determine where certain things can grow and where agriculture and forestry and tourism will flourish or fail. Note that the regional scale approach was urged in the recommendation of the Villach Conference, quoted above.

Rainfall, as all meteorologists know very well, is an elusive phenomenon, hard to predict and hard even to describe after the fact. It has great variability even under nonchanging conditions, since it is determined by a complex set of processes that include the ebb and flow of cold- and warm-air masses, the presence of mountain barriers, the amount of moisture acquired while the air was flowing over water, conditions favorable for cloud formation and convective lifting, and so forth. Thus, changes in patterns of rainfall are a secondary result of changes in atmospheric heat balance. It is therefore not surprising that the climate models do not always agree on the rainfall changes that may occur in a region, even though this may be required by planners.

This requirement poses a very great challenge to the climatological community. How can we get better information about the regional changes to be expected? Our mathematical models of the global climate system are getting better and better, as both human ingenuity and increasingly fast computers allow us to take more physical factors and interactions into account. However, the spatial resolution of the best current climate models is still about $400 \times 400$ kilometers (roughly the size of the grid used to carry out the computations), and this barely begins to give us some insight into what might happen regionally (Hansen et al., 1984; Manabe et al., 1981; Manabe and Wetherald, 1986; Washington and Meehl, 1984; Mitchell, 1983). Moreover, it is most frustrating to 
note that, when one compares the results of several experiments with different climate models to determine the effects of increased carbon dioxide, the regional changes of temperature and rainfall are often inconsistent (Schlesinger and Mitchel1, 1985; Kellogg, 1986a). Thus, climate models are apparently not yet at the stage where they can be relied upon to give us all the answers that we want, but it is certainly not too early to glean what we can from them.

There is another avenue that has been followed to get some further inklings of future climate changes, and these involve looking at past warm periods to see what happened to rainfall and the geographical patterns of growing things (Aspen Institue, 1978). We can look at anomalously warm years in this century, when the meteorological observation networks of the world were fairly well established, and we find that indeed warm years or seasons did have characteristic anomalies in rainfall distributions (Wigley et al., 1979; Williams, 1980; Jager and Kellogg, 1983). We can also look at the period some 4500 to $8000 \mathrm{yr}$ ago, the so-called Altithermal (or Hypsithermal) Period, when the world as a whole was warmer (especially in summer), and try to reconstruct the patterns of natural vegetation, lake levels, stream flows, and so forth, and from all that information get an idea of the regional differences between then and now (Nicholson and Flohn, 1980; Flohn, 1979, 1982; Kellogg, 1982; Butzer, 1980; Kutzbach and Street-Perrott, 1985; Street-Perrott and Harrison, 1985).

When these three approaches are used together, one can begin to see where there is some degree of agreement between them. Figure 4 is an attempt to do just that. (See also Pittock and Salinger, 1982, and Wigley et al., 1979). I have (in a moderately subjective way) compared the historical evidence with the climate modeling experiments on a region-by-region basis, and where there is some agreement $I$ have indicated it with a label and dashed line. Where there was disagreement I have tended to believe the evidence from the Altithermal Period. Although it was first drawn about five years ago, there has been little newer information that would compel me to change its main features. However, that is certainly not to say that Figure 4 is a firm description of the face of a warmer earth - rather, it represents a 'best guess' as to what could happen.

A number of people have studied this map of where regions could become wetter or drier in the decades ahead, and have noticed an interesting thing. According to that scenario, large agricultural areas of the superpowers (the United States, the Soviet Union, and China) are due to become drier, which may mean that their grain belts will tend to be in trouble. (What this might mean to fossil fule balance of trade has already been suggested.) At the same time, the developing countries that lie in the arid or semiarid subtropics may get more rainfall, which would obviously help them. This suggests some intriguing possibilities for rearranging the distribution of the world's 'breadbaskets'.

Some of my climatologist colleagues will not approve of these rather speculative ideas, feeling that our understanding of the climate system and the changes that it may undergo is not yet complete enough. I would have to agree in part. The important point is that we now foresee a global warming, though the time scale is not firm, and we are convinced that such a drastic climate change will bring with it major readjustments at all levels of society. Some educated speculation is in order so that we can begin to take the measure 


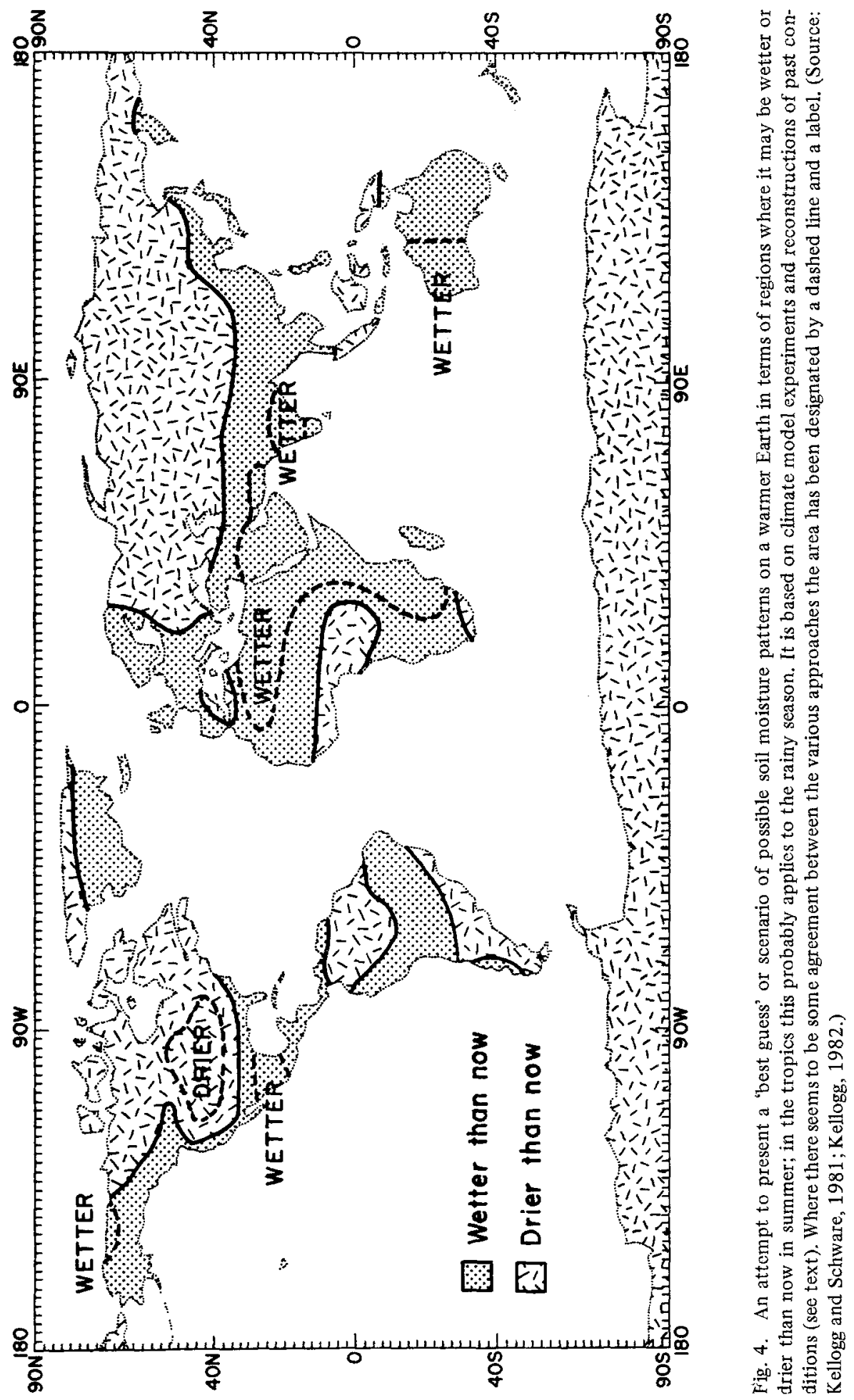


of these readjustments, and so that we can do some intelligent long-range planning.

This planning process has already begun, and I have mentioned some steps that could be taken now to mitigate the damage - steps that make sense whether or not one believes in the inevitability of climate change. However, no one seems to be very good at longrange planning, and few activities demand a planning horizon of several decades. Exceptions where future climate impacts can be anticipated are, for example, large-scale water management (building of dams and irrigation projects) and the forest products industry (multimillion-dollar tree plantations that will be harvested in $50 \mathrm{yr}$ or more) (Kellogg, 1983, 1986a). In spite of the lip-service given to studies of climate change and its societal impacts, we have yet to see an important governmental or industrial decision that actually acknowledged the climate change factor. The educational process is under way, though.

Indeed, this education process has been hastened and encouraged by several intergovernmental and scientific bodies, notably the World Meteorological Organization, the United Nations Environment Programme, the European Community, and the International Council of Scientific Unions. In the United States the Department of Energy has been sponsoring a multiyear research program that has recently climaxed in a series of excellent scientific 'state-of-the-art reviews' and a final Statement of Findings (SOF) report addressed to Congress and the public. According to the Director of this program, F. A. Koomanoff:

The SOF will summarize what we know and do not know and the degree of certainty of our knowledge. It will also present the rationale for further studies. These studies will be needed to provide an accurate scientific basis for assessments of the potential impacts of energy-related activities (Koomanoff, 1985, p. viii).

The perception of the need to study the climate system of the Earth has re-awakened the scientific community to the verity of the thought that our planet must and can be studied as one interacting whole. We now have earth-satellites and global telecommunications networks to observe it, and (equally important) super-computers capable of digesting the vast flow of new data and organizing it. There is also the inevitable realization that the biosphere must be studied along with the atmosphere, the oceans, the land surfaces, the polar regions, and the sun if we are to fathom the behavior of the system that governs our planetary environment. All this has led to a new initiative that is rapidly gaining momentum both inside and outside of scientific circles, the International Geosphere-Biosphere Program (IGBP) (NRC, 1983b; Malone and Roederer, 1985; UCAR, 1985; NASA, 1986; NRC, 1986). In the United States it has received considerable governmental attention under the banner of Earth System Science, 'a program for global change'. The question of climate change is, of course, only one aspect of the alterations that are taking place on every continent, such as the depletion of rain forests in the tropics, the spread of deserts due to bad land management, the loss of topsoil in cultivated regions, the extermination of thousands of species of plants and animals every year, and so forth (Kellogg, 1986b). 


\section{Conclusion}

The world has progressed a long way in the century since Tyndall, Chamberlin, and Arrhenius made those first tentative suggestions about mankind's ability to change the global climate. By far the biggest advances in the evolution of an awareness that this could really be true was in the 1970s. That was when the level of informed public and scientific discussion' seems to have experienced a dramatic upswing, and climate research made rapid progress on all fronts.

Carroll Wilson apparently prophesied that this was going to happen, and he was able to make it a self-fulfilling prophecy. The studies SCEP and SMIC, which he conceived and skillfully organized with the help of William Matthews and a host of friends and colleagues, were both events which were well timed, as it turned out. They achieved their goals magnificently, and inspired a generation of young scientists who would make the study of the theory of climate their life's work - and also some older ones (like myself) who would then seriously turn to research on the impacts of climate change.

To the end of his life Carroll himself remained deeply fascinated by the prospect of a global climate change, and especially with its many implications for humanity. Like some others, he felt the need to ask the next set of questions that would inevitably be raised, and sought to describe climate change in human terms. For example, Mary Wilson (his wife) tells me that in the last speech that Carroll made, when he received the Tyler Award in Nairobi, his main point was that we should address ourselves to developing new seeds which could produce food in the event of climate change.

In its broadest sense, this whole account is concerned with the development and sowing of 'new seeds'.

\section{References}

Arrhenius, S.: 1896, 'On the Influence of Carbonic Acid in the Air upon the Temperature of the Ground', Phil. Mag. 41, 237-271.

Arrhenius, S.: 1908, Worlds in the Making, Harper, New York.

Aspen Institute: 1978, The Consequences of a Hypothetical World Climate Scenario Based on an Assumed Global Warming Due to Increased Carbon Dioxide, Rept. of Symposium and Workshop, Aspen Institute for Humanistic Studies, Boulder, Colorado.

Ausubel, J. H.: 1983, 'Historical Note', Annex 2 in Changing Climate, Board on Atmospheric Sciences and Climate, National Research Council, National Academy Press, Washington, D. C., pp. 488-491.

Bryson, R. A. and Baerreis, D. A.: 1967, 'Possibilities of Major Climate Modification and Their Implications: Northwest India, a Case for Study', Bull. Amer. Meteorol. Soc. 48, 136-142.

Budyko, M. I.: 1969, 'The Effect of Solar Radiation Variations on the Climate of the Earth', Tellus 21, 611-619.

Butzer, K. W.: 1980, 'Adaptation to Global Environmental Change', Professional Geographer 32, 269-278.

Chamberlin, T. C.: 1899, 'An Attempt to Frame a Working Hypothesis of the Cause of Glacial Periods on an Atmospheric Basis', $J$. Geol., 7, 545-561.

Clark, W. C. (ed.): 1982, Carbon Dioxide Review: 1982, Oxford University Press, New York.

Coakley, J. A., Jr., Cess, R. D., and Yurevitch, F. B.: 1983, 'The Effect of Tropospheric Aerosols on the Earth's Radiation Budget: A Parameterization for Climate Models', J. Atmos. Sci. 40, 116138.

Conference Statement: 1985, International Assessment of the Role of Carbon Dioxide and of Other 
Greenhouse Gases in Climate Variations and Associated Impacts, (Villach, Austria, 9-15 October 1985), U. N. Environment Programme, World Meteorological Organization, and Intl. Council of Scientific Unions. (Complete report in press.)

Conservation Foundation: 1963, Implications of Rising Carbon Dioxide Content of the Atmosphere, The Conservation Foundation, New York, 15 pp.

Dettwiller, J. and Changnon, S. A., Jr.: 'Possible Urban Effects on Maximum Daily Rainfall Rates at Paris, St. Louis, and Chicago. J. Appl. Meteorol. 15, 517-519.

Flohn, H.: 1975, 'History and Intransitivity of Climate', in The Physical Basis of Climate and Climate Modeling, GARP Publ. Ser. No. 16, World Meteorological Organization, Geneva, pp. $106-118$.

Flohn, H.: 1979, 'A Scenario of Possible Future Climates - Natural and Man-Made', in Proceedings of the World Climate Conference, WMO No. 537, World Meteorological Organization, Geneva, Switzerland, pp. 243-268.

Flohn, H.: 1982, 'Climate Change and an Ice-Free Arctic Ocean', in W. C. Clark, (ed.) Carbon Dioxide Review: 1982, Oxford University Press, New York, pp. 143-179.

Gammon, R. H., Sundquist, E. T., and Fraser, P. J.: 1985, 'History of Carbon Dioxide in the Atmosphere', in J. R. Trabalka (ed.), Atmospheric Carbon Dioxide and the Global Carbon Cycle, Rept. DOE/ER-0239, U. S. Dept. of Energy, Washington, D. C., pp. 25-62.

Hansen, J., Lacis, A., Rind, D., Russell, G., Stone, P., Fung, I., Ruedy, R., and Lerner, J.: 1984, 'Climate Sensitivity: Analysis of Feedback Mechanisms', in J. E. Hansen and T. Takahaski (eds.), Climate Processes and Climate Sensitivity, Maurice Ewing Series No. 5, American Geophysical Union, Washington, D. C., pp. 130-163.

Hoffert, M. I. and Flannery, B. P.: 1985, 'Model Projections of the Time-Dependent Response to Increasing Carbon Dioxide', in M. C. MacCracken and F. M. Luther (eds.), Projecting the Climatic Effects of Increasing Carbon Dioxide, Rept. DOE/ER-0237, U. S. Dept. of Energy, Washington, D. C., pp. 149-190.

Idso, S. B.: 1980, 'The Climatological Significance of a Doubling of the Earth's Atmospheric Carbon Dioxide Concentration', Science 207, 1462-1463.

Idso, S. B.: 1982, Carbon Dioxide: Friend or Foe? IBR Press, Tempe, Ariz., 92 pp.

Jager, J. and Kellogg, W. W.: 1983, 'Anomalies in Temperature and Rainfall During Warm Arctic Seasons', Climatic Change 5, 39-60.

Jones, P. D., Wigley, T. M. L., and Wright, P. B.: 1986, 'Global Temperature Variation Between 1861 and 1984', Nature 322, 430-434.

Keeling, C. D., Carter, A. F., and Mook, W. G.: 1984, 'Seasonal, Latitudinal, and Secular Variations in the Abundance and Isotope Ratios of Atmospheric $\mathrm{CO}_{2}$ ', J. Geophys. Res. 89, 4615-4628.

Kellogg, W. W.: 1977, Effects of Human Activities on Global Climate, Tech. Note No. 156 (WMO No. 486), World Meteorological Organization, Geneva (47 pp.).

Kellogg, W. W.: 1979, 'Influences of Mankind or Climate', in F. A. Donath, F. G. Stehli, and G. W. Wetherill (eds.), Annual Reviews of Earth and Planetary Science, Annual Reviews Inc., Palo Alto, pp. 63-92.

Kellogg, W. W.: 1980, 'Aerosols and Climate', in W. Bach, J. Pankrath, and J. Williams (eds.), Interactions of Energy and Climate, D. Reidel Publ. Co., Dordrecht, Holland, pp. 281-296.

Kellogg, W. W.: 1982, 'Precipitation Trends on a Warmer Earth', in R. A. Reck and J. R. Hummel (eds.), Interpretation of Climate and Photochemical Models, Ozone and Temperature Measurements, American. Inst. of Physics, New York, pp. 35-46.

Kellogg, W. W.: 1983, 'Future Climate on a Warmer Earth', in W. F. Miller (ed.), Water: A Resource in Demand (Proc. Symp. on Future Climate and Potential Impacts on Natural Resources Management, Texas A \& M Univ., August 1982), Southern Cooperative Series Bul. 288, Mississippi Agxicultural Experiment Stat., Miss. State Univ., pp. 2-8.

Kellogg, W. W.: 1986a, 'How Well Can We Forecast Climate Change?' in K. Timmerhaus (ed.), Proc. AAAS Symposium on Human Intervention in the Climatology of Arid Lands: A State-of-the-Art Review, American Association for the Advancement of Science, Washington, D. C. (in press).

Kellogg, W. W.: 1986b, 'The Changing Health of Planet Earth: Observing the Earth from Space', EOS (Trans. Amer. Geophysical Union) 67, 816-819.

Kellogg, W. W., Coakley, J. A., and Grams, G. W.: 1975, 'Effect of Anthropogenic Aerosols on the 
Global Climate', in Proc. WMO/LAMAP Symp. on Long-Term Climatic Fluctuations (Norwich, U. K.), WMO Doc. 421, World Meteorological Organization, Geneva, pp. 323-330.

Kellogg, W. W., Schneider, S. H.: 1977, 'Climate, Desertification, and Human Activities', in M. H. Glantz (ed.), Desertification, Westview Press, Boulder, CO, pp. 141-164.

Kellogg, W. W. and Schware, R.: 1981, Climate Change and Society: Consequences of Increasing Atmospheric Carbon Dioxide, Westview Press, Boulder, Colorado (178 pp).

Kellogg, W. W. and Schware, R.: 1982, 'Society, Science, and Climate Change', Foreign Affairs 60, $1076-1109$.

Koomanoff, F. A.: 1985, 'Foreword', in M. C. MacCracken and F. M. Luther (eds.), Projecting the Climatic Effects of Increasing Carbon Dioxide, Rept. DOE/ER-0237, U. S. Dept. of Energy, Washington, D. C., pp. v-vii.

Kutzbach, J. E. and Street-Perrott, F. A.: 1985, 'Milankovitch Forcing of Fluctuations in the Level of Tropical Lakes from 18 to $0 \mathrm{kyr}$ BP. Nature 317, 130-134.

Malone, T. F. and Roederer, J. G.: 1985, Global Change, Publ. on behalf of ICSU Press by Cambridge University Press, Cambridge, England (512 pp.).

Manabe, S. and Wetherald, R. T.: 1967, 'Thermal Equilibrium of the Atmosphere with a Given Distribution of Relative Humidity', J. Atmos. Sci. 24, 241-259.

Manabe, S., Wetherald, R. T., and Stouffer, R. J.: 1981, 'Summer Dryness due to an Increase of Atmospheric $\mathrm{CO}_{2}$ Concentration', Climatic Change 3, 347-386.

Manabe, S. and Wetherald, R. T.: 1986, 'Reduction in Summer Soil Wetness Induced by an Increase in Atmospheric Carbon Dioxide', Science 232, 624-628.

Milankovitch, N.: 1930, 'Mathematische Klimalehre und astronomische Theorie der Klimaschwankungen', in W. Köppen and R. Geiger (eds.), Handbuch der Klimatologie I(A), Gebrüder Borntraeger, Berlin, p. 1.

Mitchell, J. F. B.: 1983, 'The Seasonal Response of a General Circulation Model to Changes in $\mathrm{CO}_{2}$ and Sea Temperature', Q. J. Roy. Meteorol. Soc. 109, 113-152.

NAS: 1979, Carbon Dioxide and Climate: A Scientific Assessment, Climate Research Board, National Academy of Sciences, Washington, D. C.

NASA: 1986, Earth System Science: A Program for Global Change (Overview), Earth System Sciences Committee, NASA Advisory Council, Natl. Aeronautics and Space Admin., Washington, D.C.

Nicholson, S. E. and Flohn, H.: 1980, 'African Environmental and Climatic Changes and the General Atmospheric Circulation in Late Pleistocene and Holocene', Climatic Change 2, 313-348.

NRC: 1983 a, Changing Climate: Report of the Carbon Dioxide Assessment Committee, Board on Atmospheric Sciences and Climate, National Research Council, Washington, D. C.

NRC: $1983 \mathrm{~b}$, Toward an International Geosphere-Biosphere Program, Rept. of a Workshop, National Research Council, Washington, D.C.

NRC: 1986, Global Change in the Geosphere-Biosphere: Initial Priorities for an IGBP, U. S. Committee for an International Geosphere-Biosphere Program, National Research Council, Washington, D. C.

Oeschger, H., Stauffer, B., Finkel, R., and Langway, C. C.: 1985, 'Variations of the $\mathrm{CO}_{2}$ Concentration of Occluded Air and of Anions and Dust in Polar Ice Cores', in E. T. Sundquist and W. S. Broecker (eds.), The Carbon Cycle and Atmospheric $\mathrm{CO}_{2}$ : Natural Variations Archean to Present, Geophysical Monograph 32, American Geophysical Union, Washington, D. C., pp. 132-142.

Pittock, A. B., and Salinger, M. J.: 1982, 'Towards Regional Scenarios for a $\mathrm{CO}_{2}$-Warmed Earth', Climatic Change 4, 23-40.

Potter, G. L., Kiehl, J. T., and Cess, R. D.: 1987, 'A Clarification of Certain Issues Related to the $\mathrm{CO}_{2}$-Climate Problem', Climatic Change 10, 87-95.

PSAC: 1965, Restoring the Quality of Our Environment, Report of the Environmental Pollution Panel, President's Science Advisory Committee, The White House, Washington, D. C.

Ramanathan, V.: 1981, 'The Role of Ocean Atmosphere Interactions in the $\mathrm{CO}_{2}$ Problem', J. Atmos. Sci. 38, 918-930.

Ramanathan, V., Singh, H. B., Cicerone, R. J., and Kiehl, J. T.: 1985, 'Trace Gas Trends and Their Potential Role in Climate Change', $J$. Geophys. Res. 90, 5547-5566.

Rasmussen, R. A. and Khalil, M. A. K.: 1986, 'Atmospheric Trace Gases: Trends and Distributions over the Last Decade', Science 232, 1623-1624. 
Revelle, R.: 1985, 'Introduction: The Scientific History of Carbon Dioxide', in E. T Sundquist and W. S. Broecker (eds.), The Carbon Cycle and Atmospheric $\mathrm{CO}_{2}$ : Natural Variations Archean to Present, Geophysical Monograph 32, American Geophysical Union, Washington, D. C., pp. 1-4.

Revelle, R. and Suess, H. E.: 1957, 'Carbon Dioxide Exchange Between Atmosphere and Ocean and the Question of an Increase of Atmospheric $\mathrm{CO}_{2}$ During the Past Decades', Tellus 9, 18-27.

Rotty, R. M. and Masters, C. D.: 1985, 'Carbon Dioxide from Fossil Fuel Combustion: Trends, Resources, and Technological Implications', in J. R. Trabalka (ed.), Atmospheric Carbon Dioxide and the Global Carbon Cycle, Rept. DOE/ER-0239, U. S. Dept. of Energy, Washington, D. C.

Rotty, R. M. and Marland, G.: 1986, "Fossil Fuel Combustion: Recent Amounts, Patterns, and Trends of $\mathrm{CO}_{2}{ }^{\prime}$, in J. R. Trabalka and D. E. Reichle (eds.), The Changing Carbon Cycle: A Global Analysis, Springler-Verlag, New York.

Sagan, C., Toon, O. B., and Pollack, J. B.: 1979, 'Anthropogenic Albedo Changes and the Earth's Climate', Science 206, 1363-1368.

SCEP: 1970, Man's Impact on the Global Climate: Report of the Study of Critical Environmental Problems, The MIT Press, Cambridge, Mass, $319 \mathrm{pp}$.

Schlesinger, M. E. and Mitchell, J. F. B.: 1985, 'Model Projections of Equilibrium Response to Increased $\mathrm{CO}_{2}$ Concentration', in M. C. MacCracken and F. M. Luther (eds.), Projecting the Climatic Effects of Increasing Carbon Dioxide, Rept. DOE/ER-0237, U. S. Dept. of Energy, Washington, D. C. 81-148.

Schneider, S. H., Kellogg, W. W., and Ramanathan, V. (also C. B. Leovy in separate letter): 1980, 'Letters to the Editor', Science 210, 6-7.

Schneider, S. H., and Thompson, S. L.: 1981, 'Atmospheric $\mathrm{CO}_{2}$ and Climate: Importance of the Transient Response', J. Geophys. Res. 86, 3135-3147.

Sellers, W. D.: 1969, 'A Global Climate Model Based on the Energy Balance of the Earth-Atmosphere System', J. Appl. Meteorol. 8, 329-400.

Smagorinsky, J.: 1983, 'Effects of Carbon Dioxide', in Changing Climate, Board on Atmospheric Sciences and Climate, National Research Council, Washington, D. C., pp. 266-284.

SMIC: 1971, Inadvertent Climate Modification: Report of the Study of Man's Impact on Climate, The MIT Press, Cambridge, Mass., 308 pp.

Street-Perrott, F. A. and Harrison, S. P.: 1984, 'Temporal Variations in Lake Levels Since $30000 \mathrm{yr}$ BP: An Index of the Global Hydrological Cycle', in J. E. Hansen and T. Takahashi (eds.), Climate Processes and Climate Sensitivity, Geophysical Monograph 29, American Geophysical Union, Washington, D. C., pp. 118-129; see also, by same authors, 1985: 'Lake Levels and Climate Reconstruction', in A. D. Hecht (ed.), Paleoclimatic Analysis and Modeling, John Wiley \& Sons, New York, pp. 291-340.

Tolman, C. F. Jr.: 1899, 'The Carbon Dioxide of the Ocean and Its Relations to the Carbon Dioxide of the Atmosphere', J. Geol. 7, 585-601.

Tyndall, J.: 1863, 'On Radiation Through the Earth's Atmosphere', Phil. Mag. 4, 200-207.

UCAR: 1985, Opportunities for Research at the Atmosphere/Biosphere Interface, Univ. Corp. for Atmospheric Research, Boulder (27 pp.).

Von Neumann, J.: 1955, 'Can We Survive Technology?', Fortune, June issue.

Wallen, C. C.: 1980, 'Monitoring Potential Agents of Climate Change', Ambio 9, 222-228.

Washington, W. M. and Meehl, G. A.: 1984, 'Seasonal Cycle Experiment on the Climate Sensitivity Due to a Doubling of $\mathrm{CO}_{2}$ with an Atmospheric General Circulation Model Coupled to a Simple Mixed-Layer Ocean Model', J. Geophys. Res. 89, 9475-9503.

Weisburd, S.: 1986, 'Hope for International Ozone Accords', Science News 130, p. 196.

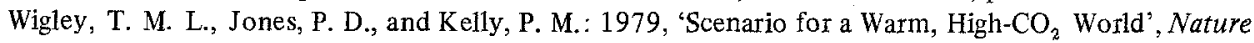
283, $17-20$.

Williams, J.: 1980, 'Anomalies in Temperature and Rainfall During Warm Arctic Seasons as a Guide to the Formulation of Climate Scenarios', Climatic Change 2, 249-266.

Wilson, C. L. (Project Director): 1980, Coal - Bridge to the Future: Report of the World Coal Study (WOCOL), Ballinger Publishing Company, Cambridge, Mass.

WMO: 1975, Proceedings of the WMO/IAMAP Symposium on Long-Term Climatic Fluctuations, (Norwich, 18-23 August 1975), World Meteorological Organization Rept. WMO No. 421, Geneva, Switzerland. 
WMO: 1979, Proceedings of the World Climate Conference, (Geneva, 12-13 February 1979), World Meteorological Organization Rept. No. 537, Geneva, Switzerland.

WMO: 1982, Detection of Possible Climate Change. Rept. of the JSC/CAS Meeting of Experts (Moscow, October 1982), ed. by W. W. Kellogg and R. D. Bojkov, World Climate Programme Rept. No. 29, World Meteorological Organization, Geneva, Switzerland.

(Received 20 March 1986; in revised form 10 October 1986) 